\title{
2 - Field measurements of soil respiration: principles and constraints, potentials and limitations of different methods
}

\author{
Jukka Pumpanen, Bernard Longdoz and Werner L. Kutsch
}

\subsection{INTRODUCTION}

Soil respiration is a major component in the carbon balance of terrestrial ecosystems and has been measured in the field for more than eight decades. In this chapter, we will describe the measurement of soil $\mathrm{CO}_{2}$ efflux at the soil surface that can be considered as equivalent to soil $\mathrm{CO}_{2}$ production when integrated over long time periods (week, month or season). At shorter time scales the transport of $\mathrm{CO}_{2}$ may uncouple the soil $\mathrm{CO}_{2}$ efflux from its production inside the soil. Different methods have been developed to measure this efflux. These methods can affect the object being measured by disturbing the biochemical processes involved in $\mathrm{CO}_{2}$ production, the physical properties influencing $\mathrm{CO}_{2}$ movement towards the soil surface, or by changing the environmental conditions in the soil. Therefore, soil respiration measurements in the field are one of the most difficult among the ecosystem flux measurements. So far, no single method has been established as the standard but comparisons, which give important indications on their accuracy, have been performed. The choice of the measurement methodology is not limited to that of a measurement system. The experimenter has to elaborate a protocol depending on the temporal and spatial scales studied. In this chapter, we will describe the most commonly used methodologies for measuring soil $\mathrm{CO}_{2}$ efflux and present their history, principles and constraints (Section 2.2). In addition, we will present a number of major error sources associated with the different methods and the ways to avoid them (Section 2.3), describe a comparison between different systems (Section 2.4) and give recommendations for the measurement protocol (Section 2.5).

\subsection{MEASUREMENT PRINCIPLES AND HISTORY OF TECHNICAL DEVELOPMENTS}

Soil respiration chambers can be grouped in three categories based on their working principle. A schematic presentation of the working principle and flux calculation of different chamber types is presented in Fig. 2.1. In closed chambers, the $\mathrm{CO}_{2}$ flux is determined from the concentration increase within the chamber's headspace during a known period of time (Fig. 2.1, upper part). Closed chambers can further be divided into two major categories: closed dynamic chambers (also known as non-steady-state flow-through chambers) and closed static chambers also known as non-steady-state non-flow-through chambers). In open chambers (also known as steady-state flow-through chambers) the $\mathrm{CO}_{2}$ efflux is determined from the difference between $\mathrm{CO}_{2}$ concentration at the inlet and outlet of the chamber (Fig. 2.1, lower panel).

The Swedish scientist Henrik Lundegårdh (1922; $1924 ; 1927)$ was the first to start with measurements of soil respiration in the field. Lundegårdh used a chamber ('respiration bell', Fig. 2.2) with a collar that was driven into the soil. Since there was no exchange with the surrounding air the system was coined a 'closed static' in the later systematic of the methods. The $\mathrm{CO}_{2}$ concentration inside the respiration bell increased proportionally to the soil respiration. After 10 to 20 minutes Lundegardh took small samples of air from the chamber, which were analyzed in a self-constructed 'apparatus for accurate analysis of the $\mathrm{CO}_{2}$ concentration in the air'. This apparatus was based on the absorption of $\mathrm{CO}_{2}$ by a mixture of $\mathrm{KOH}$ and $\mathrm{Ba}(\mathrm{OH})_{2}$ and the 

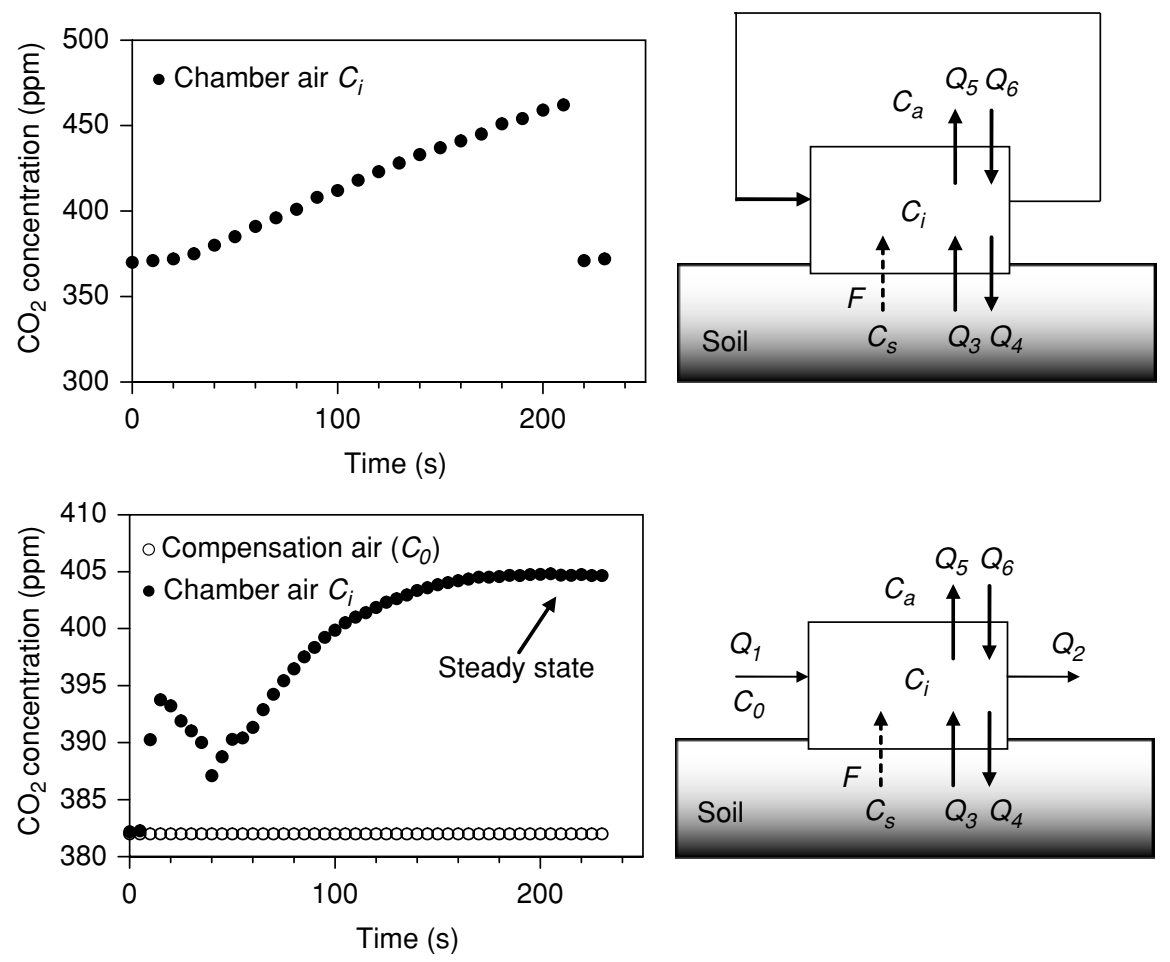

Figure 2.1 (Upper panel) In a closed chamber (dynamic or static) the $\mathrm{CO}_{2}$ efflux rate can be calculated from the slope of the $\mathrm{CO}_{2}$ concentration increase within the chamber $\left(C_{i}\right)$. Similarly, possible air flows between the soil air space and the chamber $\left(Q_{3}\right.$ and $\left.Q_{4}\right)$ as well as between the ambient air and the chamber $\left(Q_{5}\right.$ and $\left.Q_{6}\right)$ can generate additional mass flow of $\mathrm{CO}_{2}$ in and out of the chamber. When designing both chamber types, air flows of type $Q_{3}, Q_{5}$ or $Q_{6}$ should be avoided. The $\mathrm{CO}_{2}$ efflux from soil $(F)$ can be determined using Eq. (2.1).

(Lower panel) The $\mathrm{CO}_{2}$ concentration in an open chamber depends on $\mathrm{CO}_{2}$ concentrations $\left(C_{0}\right.$ and $\left.C_{i}\right)$ and flow rates of the incoming and outgoing air flows $\left(Q_{J}\right.$ and $Q_{2}$, which should be equal to avoid pressure differences). In addition, possible air flows $\left(Q_{3}\right.$ and $\left.Q_{4}\right)$ between the soil air space and the chamber as well as between the ambient air and the chamber $\left(Q_{5}\right.$ and $\left.Q_{6}\right)$ can generate additional mass flow of $\mathrm{CO}_{2}$ in and out of the chamber and should also be avoided. When a steady-state concentration in the chamber has been reached, the $\mathrm{CO}_{2}$ efflux from soil $(F)$ can be determined from the mass balance shown in Eq. (2.2).

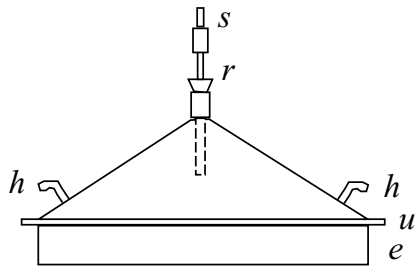

Figure 2.2 Lundegårdh's respiration bell.

measurement of the induced volume change. Between 1921 and 1925 Lundegårdh made a large number of soil respiration measurements combined with measurements of soil temperature, moisture, soil properties, manure and even $\mathrm{CO}_{2}$ profiles in the soil as well as in the lowest parts of the atmosphere. Thus, he was able to make a first analysis of the regulation of soil respiration by climatic and edaphic factors.

The introduction of the first 'open dynamic chamber' by Porkka (1931) was motivated by the observation that the increasing $\mathrm{CO}_{2}$ concentration in the closed chamber could reduce the gradient that is driving the diffusive transport. He used a round chamber with an inlet at its top and analyzed the air sucked through this chamber by absorbing the $\mathrm{CO}_{2}$ in $\mathrm{Ba}(\mathrm{OH})_{2}$ and titration thereafter. In parallel, he analyzed the air at $5 \mathrm{~cm}$ above the soil surface and calculated the soil respiration from the difference in the measured $\mathrm{CO}_{2}$ concentration. 
With Porkka's publication the never ending competition between open and closed systems was opened, and it is interesting to read that most of the important arguments were exchanged even during this early stage of the discussion and eternally repeated thereafter.

Closed chambers seal a certain area of the soil surface completely from the ambient air. They can be further distinguished after the way the $\mathrm{CO}_{2}$ efflux is determined. In closed static accumulation chambers, the $\mathrm{CO}_{2}$ coming from the soil accumulates inside. The $\mathrm{CO}_{2}$ concentration increase is determined from air sampled with a syringe and analyzed separately with a $\mathrm{CO}_{2}$ analyzer (in former times, as Lundegårdh (1927) did, by titration, or as nowadays with either an infrared gas analyzer or a gas chromatograph). Then, the soil efflux $(F)$ in $\mu$ mol $\mathrm{m}^{-2}$ per unit of time $(t)$ can be calculated from the increase of the $\mathrm{CO}_{2}$ concentration within the chamber $\frac{\Delta C_{i}}{\Delta t}$, the chamber volume $\left(V_{c}\right)$, the molar volume $\left(V_{m o l}\right)$ and the covered soil area $(A)$ :

$$
F=\frac{\Delta C_{i}}{\Delta t} \cdot \frac{V_{c}}{V_{m o l} \cdot A}
$$

The $V_{\text {mol }}$ corresponds to the molar volume $\mathrm{m}^{3} \mathrm{~mol}^{-1}$ (approx $22.4 \cdot 10^{-3} \mathrm{~m}^{3} \mathrm{~mol}^{-1}$ for ideal gas) and is thus equal to $8.314 \mathrm{~J} \mathrm{~K}^{-1} \mathrm{~mol}^{-1} \cdot \mathrm{T}_{\mathrm{air}} / \mathrm{P}_{\mathrm{atm}}$.

Another application of the closed static system is the closed static absorption method that was introduced by Lundegårdh (1922). The $\mathrm{CO}_{2}$ coming from the soil is usually trapped with chemicals such as $\mathrm{NaOH}$ or soda lime placed within the chamber. They can be used either as solutions, which are titrated thereafter, or as grains that are dried and weighed. Thus, the $\mathrm{CO}_{2}$ concentration within the chamber remains relatively stable. The $\mathrm{CO}_{2}$ efflux can be calculated from the amount of $\mathrm{CO}_{2}$ bound in the trapping chemical. When soda lime is used for the trapping, the soil efflux measured has also to be corrected to account for the water release during the chemical reaction between $\mathrm{CO}_{2}$ and soda lime (Edwards, 1982; Grogan, 1998; Janssens et al., 2000). The advantage of the adsorption method over the accumulation method is that it can integrate over periods up to 24 hours and can easily be applied simultaneously at tens or hundreds of soil chambers (Haber, 1958; Janssens and Ceulemans, 1998). The last kind of closed system is the dynamic one, where the air circulates between the $\mathrm{CO}_{2}$ analyzer and the chamber. At each passage through the chamber the soil efflux adds some $\mathrm{CO}_{2}$ to the air and the $\mathrm{CO}_{2}$ concentration increases regularly. The soil efflux is then calculated using Eq. (2.1).

In open systems, ambient air is continuously sucked through the chamber. The $\mathrm{CO}_{2}$ concentration within the chamber (Fig. 2.1) reaches steady-state (equilibrium) after a period of time. Then, the $\mathrm{CO}_{2}$ flux from the soil into the chamber is balanced by the transport of $\mathrm{CO}_{2}$ by the air stream through the chamber, and the soil respiration rate $(F)$ is determined from the difference between the $\mathrm{CO}_{2}$ concentration at the inlet and the outlet of the chamber $\left(\triangle C O_{2}=C_{i}-C_{0}\right.$ in Fig. 2.1, lower panel), the through-flow rate $\left(\Phi, Q_{l}=Q_{2}\right.$ in Fig. 2.1, lower panel) and the soil covered area $(A)$ :

$$
F=\Delta \mathrm{CO}_{2} \cdot \frac{\Phi}{A}
$$

However, open systems were not used very often, because they required a higher amount of samples to analyze and a facility to pump the air through the chamber (Porkka used a 12.6 L bottle of water that he slowly emptied). Therefore, the time of open systems did not dawn until about 20 years later when infrared gas analyzers (IRGA) and electrical membrane pumps became available. The first soil respiration system using an IRGA was an open system developed by H. Koepf (1953a). This first open dynamic system gave promising results (Koepf, 1953b, 1954), but was only useful for stationary measurements close to the laboratory, because the IRGA alone was $115 \mathrm{~cm}$ high and weighed about $50 \mathrm{~kg}$. In addition, the system needed grid power.

Consequently, the closed 'Lundegardh bell' remained the standard method for another 20 years, either in the original way with the extraction of an air sample after 10 to 20 minutes or with an amount of absorbent placed inside the chamber.

With the further development of electronics smaller IRGAs became available and more open systems were developed for field measurements (Witkamp, 1969; Witkamp and Frank, 1969; Edwards and Sollins, 1973; Edwards, 1974; Kanemasu et al., 1974; Schwartzkopf, 1978). They enabled much more accurate and continuous measurements as close as possible to the natural conditions. A large variety of systems developed at different research institutions are based on the open chamber technique (Fang and Moncrieff, 1996; Kutsch, 1996; Iritz et al., 1997; Kutsch and Kappen, 1997; Rayment and Jarvis, 1997; Fang and Moncrieff, 


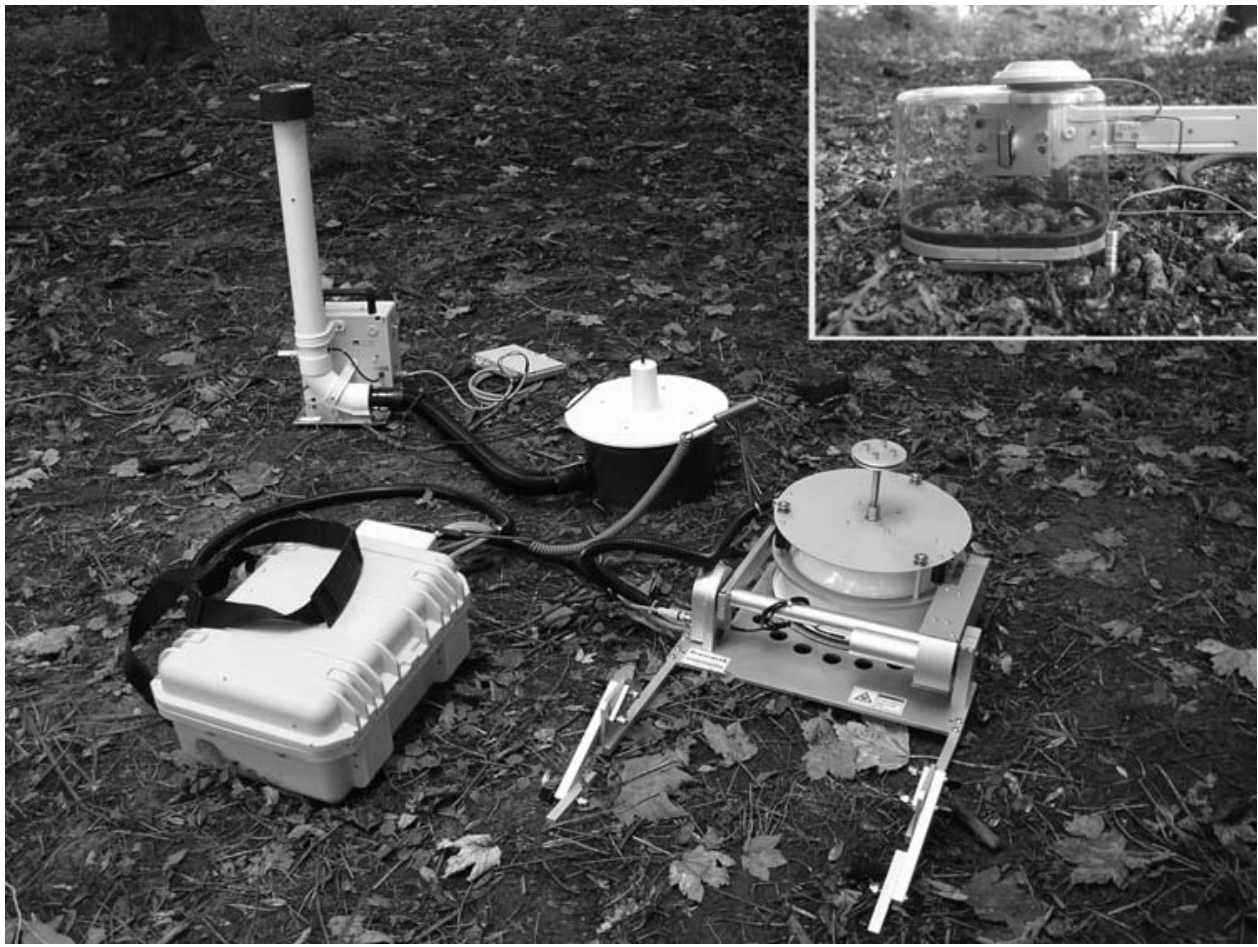

Figure 2.3 Open dynamic chamber systems from different manufacturers. PP-Systems CFX-1 at the back and ADC SRS-1000 in the small figure. Automatic closed dynamic system Li-Cor Li-8100 chamber at the front is based on closed dynamic technique.

1998; Longdoz et al., 2000; Rayment, 2000; Kutsch et al., 2001; Pumpanen et al., 2001, 2004) Recently, commercial open systems have also become available (Fig. 2.3).

Closed systems were also further developed with the technical development in electronics that provided smaller and much better portable IRGAs. Modern 'closed dynamic' systems recycle the air from the chamber to the analyzer and back, and can monitor the increase in concentration continuously (Fig. 2.1, upper panel, right). In addition, they may scrub the increased $\mathrm{CO}_{2}$ at the end of a measurement cycle by means of a soda lime column to start a new measurement automatically. Portability and short measuring times in closed dynamic chambers allow the measurement of a high number of frames or collars within a big area, and therefore the estimation of the heterogeneity of soil respiration. Most of the commercial systems are based on the closed dynamic chamber technique (LiCor, PPsystems, ADC, Figs. 2.3, 2.4 and 2.5) but also a lot of researchers went this way (Rochette et al., 1992;
Goulden and Crill, 1997; Rochette et al., 1997; Davidson et al., 2002; Savage and Davidson, 2003).

Two more techniques are commonly used to determine soil respiration in the field: ground level eddy covariance (Norman et al., 1992) and concentration gradients (Albertsen, 1979). The eddy covariance (EC) system is composed of a sonic anemometer and an infrared gas analyzer measuring respectively at the same point the three components of the wind speed and the $\mathrm{CO}_{2}$ concentration at high frequency $(10 \mathrm{~Hz}$ or more). With these measurements, it is possible to deduce the $\mathrm{CO}_{2}$ vertical turbulent flux equal to the mean product of the fluctuations of the vertical wind speed and the $\mathrm{CO}_{2}$ concentration. It can be demonstrated with fluid mechanic equations (Aubinet et al., 2000) that, according to few assumptions, this vertical turbulent flux at any point above an ecosystem can be equal to the net quantity of $\mathrm{CO}_{2}$ produced or absorbed by this ecosystem. The principal assumptions are the horizontal homogeneity of the ecosystem and a relatively high level of turbulence (high enough to neglect the transport of $\mathrm{CO}_{2}$ by 

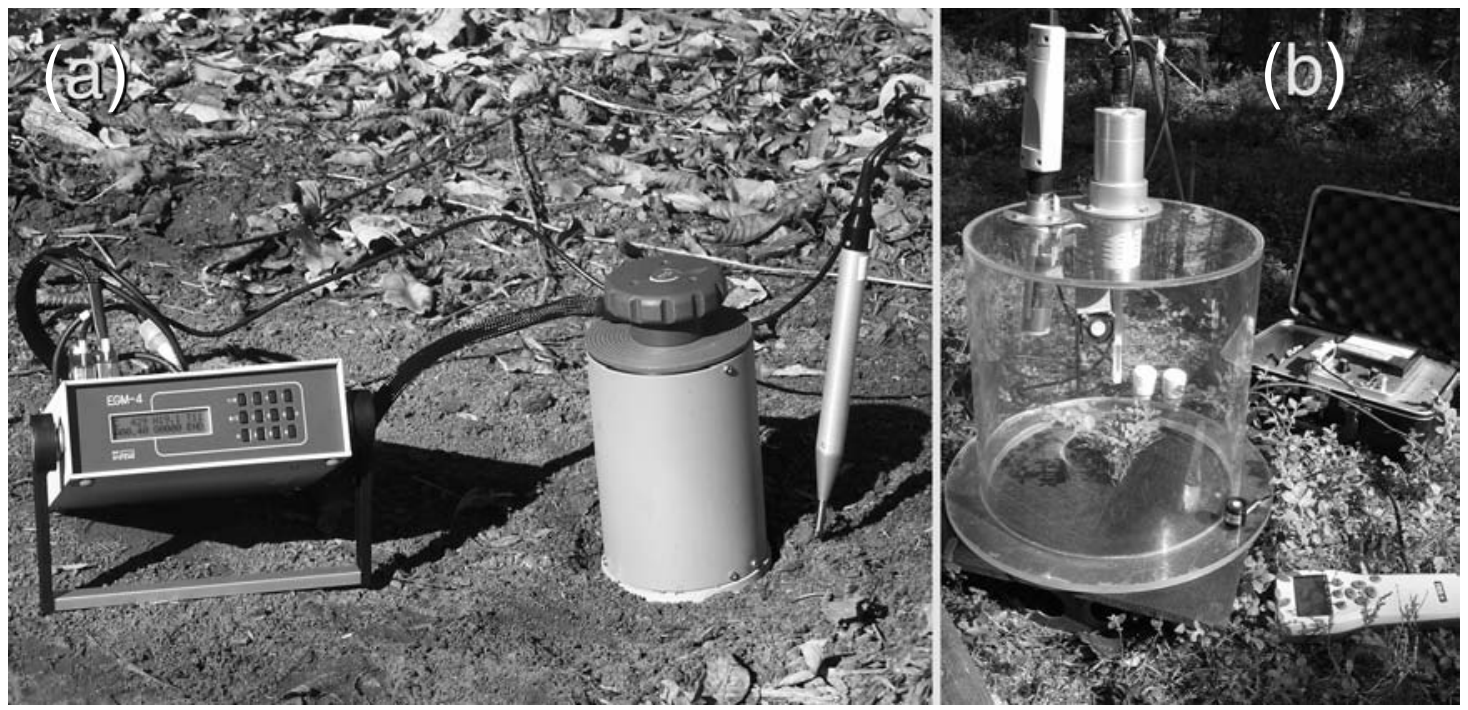

Figure 2.4 Closed chamber systems from different manufacturers (a) PP-Systems SRC-1 closed dynamic chamber, (b) Vaisala GMP-343 $\mathrm{CO}_{2}$ probe connected to a closed chamber made by Tunkua Oy, Finland. In the figure, a transparent chamber is being used for measuring photosynthesis of ground vegetation.

advection and the $\mathrm{CO}_{2}$ storage between the measurement point and the soil). Eddy covariance systems are now frequently installed on towers above forests, grasslands and crops (Law et al., 1999) to measure their net ecosystem exchange.

In several studies EC systems were mounted within the trunk space of forests to quantify the soil $\mathrm{CO}_{2}$ efflux (Norman et al., 1997; Kelliher et al., 1999; Janssens et al., 2001; Shibistova et al., 2002). This is problematic because the presence of tree crowns prevents eddy penetration below the canopy to the measurement level. Thus, the turbulence characteristics close to the forest floor may lead to a bias in the measurements or can induce large time periods with turbulence being too low for a good functioning of the EC system. However, using data coming from forests with a relatively open canopy and, more particularly, selecting measurements performed during a windy period (data quality control routines exist), it might be possible to obtain interesting quantitative information on forest soil $\mathrm{CO}_{2}$ efflux. The other difficulties introduced by the EC method are the determination of the footprint area and the impossibility to separate vegetation and soil signals, which implies that EC is not really applicable for soil $\mathrm{CO}_{2}$ efflux measurements on vegetated surfaces. The most important problem in forests with relatively open canopies, in crop lands and in grasslands is the presence of understorey and ground vegetation. An EC system installed at one or few metres height is then unable to separate the soil and ground vegetation contribution to the net flux. These restrictions reduce the possibilities of using ground level EC systems to measure soil $\mathrm{CO}_{2}$ efflux, even if it minimizes disturbance at the soil surface and covers a larger area than chambers do.

Soil $\mathrm{CO}_{2}$ effluxes can also be derived from $\mathrm{CO}_{2}$ concentration gradients between soil and the atmosphere, and between different soil layers. Carbon dioxide concentration in the soil air space between soil particles is often an order of magnitude higher than in the atmosphere (Fernandez and Kosian, 1987; Suarez and Šimunek, 1993), resulting in a large concentration gradient between the soil and the atmosphere. The primary mechanism for transporting $\mathrm{CO}_{2}$ from the soil to the atmosphere is molecular diffusion (Freijer and Leffelaar, 1996). According to Fick's first law, the gas flux is dependent on the concentration gradient and the diffusivity of the soil. Thus the $\mathrm{CO}_{2}$ flux in the soil is usually upwards, resulting in a $\mathrm{CO}_{2}$ efflux out of the soil (Fig. 2.6). The diffusion of $\mathrm{CO}_{2}$ depends essentially on the total porosity of soil layers, soil water 


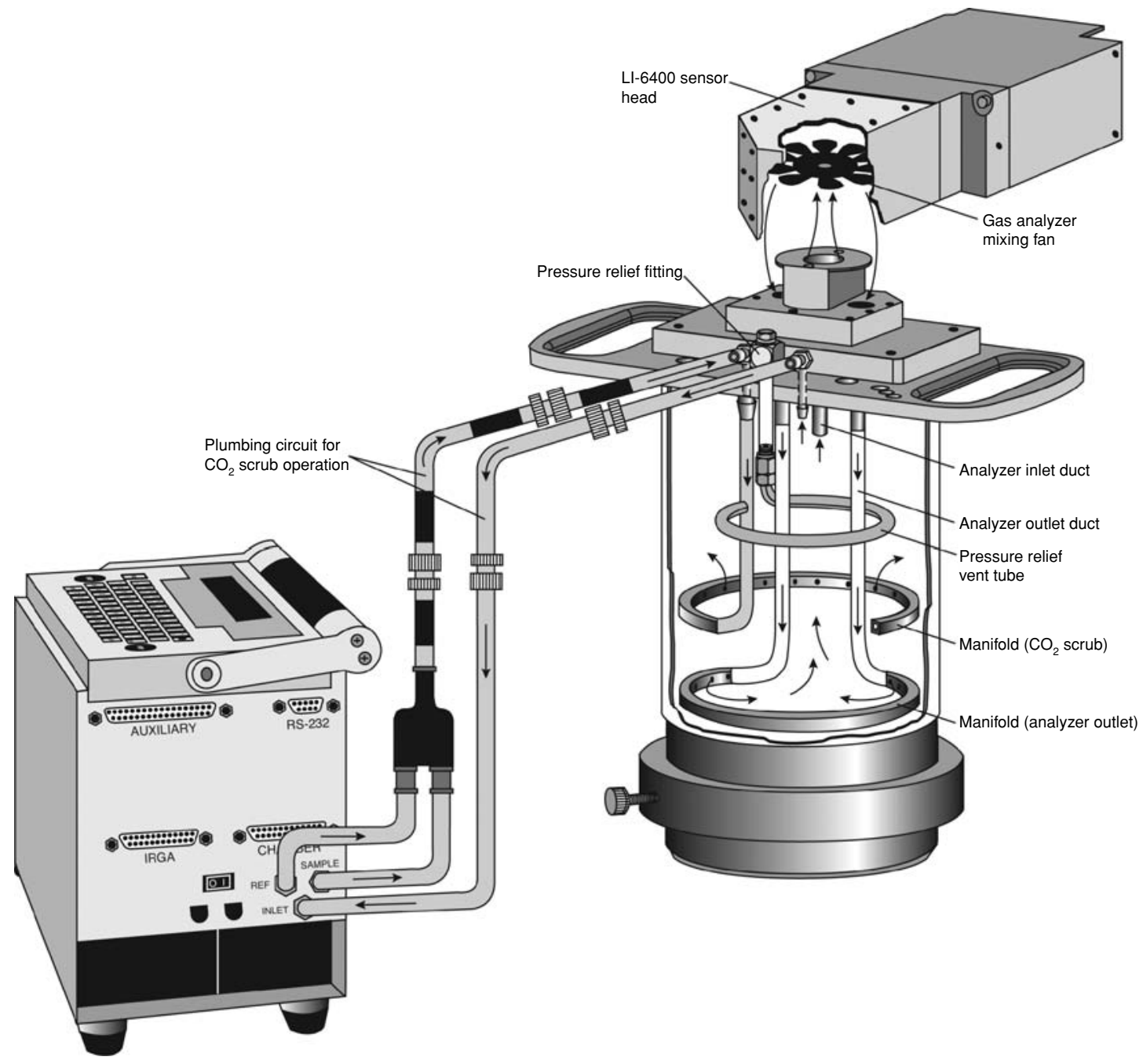

Figure 2.5 An example of the air circulation in a closed dynamic chamber (Li-Cor 6400-09). The air is pumped from the chamber to the IRGA and returned back to the chamber through a perforated manifold. The pressure equilibrium tube is located on top of the chamber (extract from Li-Cor 6400-09 Soil $\mathrm{CO}_{2}$ flux chamber instruction manual, with the kind permission of Li-Cor Inc., Nebraska USA). In the PP-Systems chamber, the air is mixed by a fan installed in the upper part of the chamber.

content, layer thickness and the concentration gradient between the layers. Gradients of $\mathrm{CO}_{2}$ concentration are difficult to convert into fluxes because the diffusivity of the soil is heterogeneous and also changes with soil moisture. Despite these difficulties, some studies have been conducted with this technique during recent years (Tang et al., 2003; Pumpanen et al., 2003a, 2003b; Jassal et al., 2004; Tang et al., 2005; Pihlatie et al., 2007, Mykeebust et al., 2008).
The next sections will provide more detailed information on the possible disturbances involved in the measurement systems and the ways to avoid them.

\subsection{DISTURBANCES INTRODUCED BY THE MEASUREMENT SYSTEM}

Systematic errors can be introduced into the flux measurement by disturbing the physical processes involved 


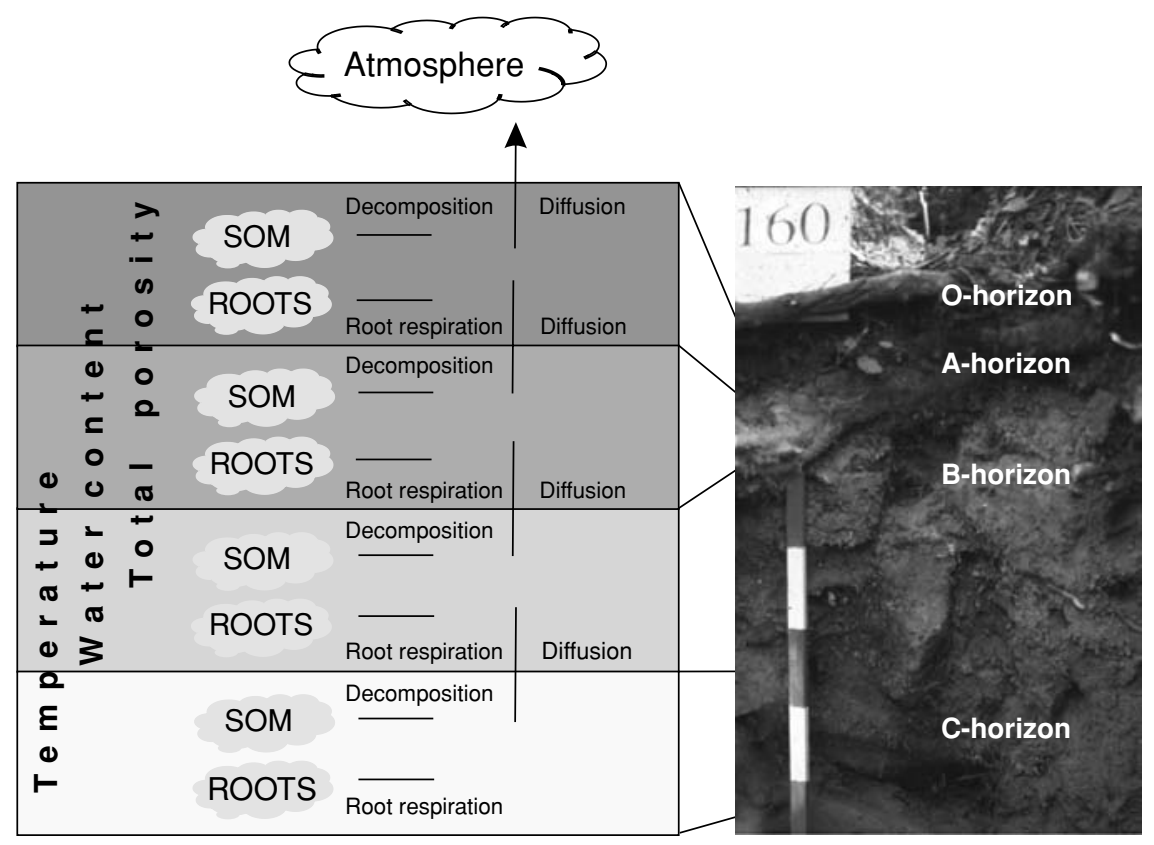

Figure 2.6 Schematic presentation of the soil profile and processes underlying soil $\mathrm{CO}_{2}$ efflux.

in $\mathrm{CO}_{2}$ movement within the soil or by modifying the biochemical processes involved in soil $\mathrm{CO}_{2}$ production. This last disturbance can be induced directly or indirectly by changes in the soil environmental conditions. This section presents these disturbances and the ways to overcome them.

A chamber measurement system does not determine directly the soil $\mathrm{CO}_{2}$ production but the soil $\mathrm{CO}_{2}$ efflux. For long-term integration (month or season) these two fluxes can be considered as equivalent. The $\mathrm{CO}_{2}$ is transported through the soil surface mainly by molecular diffusion but can also be driven by wind (advection or turbulence). Fang and Moncrieff(1999) as well as Lund et al. (1999) provide theoretical derivations and model formulations for these two ways of transport.

\subsubsection{Vertical pressure gradient}

In open and closed dynamic chamber systems the artificial air circulation generated by the pump can modify the air pressure just above the soil and thus perturb the vertical pressure gradient. Even a small pressure difference between the inside of the chamber and the atmosphere (PDC), as low as $1 \mathrm{~Pa}$, has been shown to cause significant errors to the measured $\mathrm{CO}_{2}$ efflux

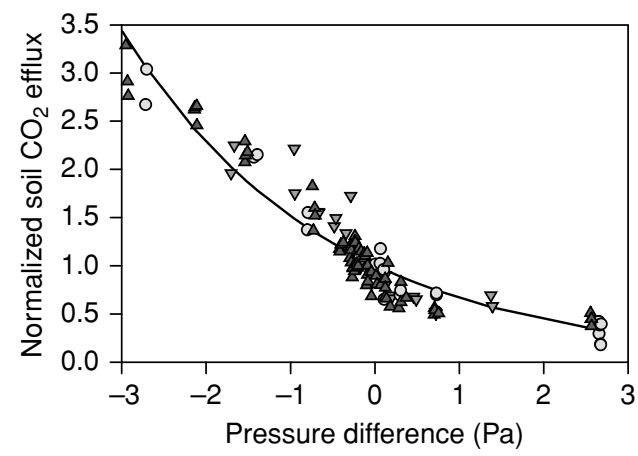

Figure 2.7 Effect of a constant pressure difference between the inside and the outside of the chamber (PDC) on soil $\mathrm{CO}_{2}$ efflux in the forest of Vielsalm (Belgium). The flux is normalized by its value at $\mathrm{PDC}=0$ and negative PDC corresponds to a pressure in the chamber being lower than the atmospheric pressure.

(Kanemasu et al., 1974; De Jong et al., 1979; Fang and Moncrieff, 1996; Kutsch, 1996; Fang and Moncrieff, 1998; Lund et al., 1999; Longdoz et al., 2000; Kutsch et al., 2001). Figure 2.7 shows an example of the dependence of soil $\mathrm{CO}_{2}$ efflux on the PDC for the forest soil of Vielsalm in Belgium.

In a closed dynamic chamber, the reproduction of the natural vertical pressure gradient near the soil 
surface is the main problem (Kanemasu et al., 1974; De Jong et al., 1979; Fang and Moncrieff, 1998). In these systems, pumps may create an overpressure or underpressure at its two faces. The air circulates from the overpressure face to the underpressure face along a pressure gradient. The pressure at any point is constant and depends only on its position in the circuit. Thus, the pressure in the chamber can be lower or higher than in the atmosphere. Underpressure generates an artificial mass flow of $\mathrm{CO}_{2}$ from the soil into the chamber and leads to an overestimation of the efflux, whereas overpressure can block the natural $\mathrm{CO}_{2}$ efflux from the soil leading to an underestimation (Norman et al., 1992; Striegl et al., 1992).

The $\mathrm{CO}_{2}$ efflux is more sensitive to the suction of air than to a slight overpressure especially in a porous soil (Longdoz et al., 2000; Pumpanen et al., 2001). The mass flow of $\mathrm{CO}_{2}$ from soil pores also increases with increasing pore space $\mathrm{CO}_{2}$ concentration. Thus the impact of the PDC increases with the permeability and $\mathrm{CO}_{2}$ productivity of the soil. To reduce the PDC, some chambers have a small hole with a tube connecting the inside and outside of the chamber and maintaining the pressure equilibrium. Unfortunately, this tube is not always sufficient to transmit the high-frequency atmospheric pressure fluctuations into the chamber, which can have a significant impact on the soil efflux measurement (Longdoz et al., 2000; Pumpanen et al., 2001; Takle et al., 2004).

Another possible origin of PDC in closed dynamic chambers is the effect of the air mixing inside the chamber. In closed chambers, the determination of $\mathrm{CO}_{2}$ efflux is based on the assumption that the concentration is homogeneous within the chamber's headspace (Fig. 2.1). In some commercial systems (e.g. Li-Cor), the air mixing is assured by extracting the sample air from the upper part of the chamber and by pushing air from the analyzer back into the chamber through a perforated manifold circulating around the chamber. In PP-systems SRC-1 chamber, the air is mixed by a fan installed on top of the chamber and inducing a vertical air flow in the chamber's headspace. Inevitably, the air mixing changes the natural turbulent conditions in the chamber. The perturbation provoked can be significantly reduced when small airflow is used or when the turbulence generated by the fan is reduced by placing a metal mesh between the fan and the soil surface. This latter option is used in the latest version of the
PP-systems soil respiration chamber. For all the closed chambers a measurement of the PDC value is recommended before starting measurements.

In open systems, pressure problems arise if the inlet size and through-flow are not balanced such that pressure differences occur, or if an open system does not only transmit but also modifies the natural pressure fluctuations due to an inappropriate design of the chamber inlet. For example, Kutsch et al. (2001) placed the inlet at one side of the chamber and thus caused an overpressure inside the chamber when the wind blew directly towards the inlet and an underpressure with all other wind directions. Therefore, the open chamber system has to be designed very carefully to avoid artificial underpressure or overpressure during the measurements.

Pump(s) can also induce PDC in open chamber systems (Rayment and Jarvis, 1997; Fang and Moncrieff, 1998) if the inlet and outlet airflow are not the same. Flow rate differences can be induced by the resistance at the inlet or outlet of the chamber. It may not be enough just to let the air be drawn into or out of the chamber. Even if the inlet and the outlet are large in diameter, there is always a small PDC as long as the air is only sucked into or out of the chamber. Preferably, an equal amount of compensating air should be fed into the chamber as is drawn out of the chamber. Separate pumps and mass flow controllers can be used to control the flow rates of air in and out of the chamber. Basically, this is the only way to avoid the pressure effect. However, in practice mass flow controllers can not reproduce the natural pressure fluctuation induced by the wind just above the soil surface. Nevertheless, at least systematic PDC caused by suction of air can be avoided by using separate pumps and mass flow controllers on both sides of the chamber. If it is not possible to organize separate pumps and mass flow controllers, it is of utmost importance to monitor the PDC to detect the possible pressure differences.

\subsubsection{Vertical $\mathrm{CO}_{2}$ concentration gradient}

By contrast to the EC and gradient systems, all of the chamber systems can disturb the vertical $\mathrm{CO}_{2}$ concentration gradient in different ways. They may modify the air $\mathrm{CO}_{2}$ concentration in the chamber or disturb the soil $\mathrm{CO}_{2}$ concentration by perturbing soil production directly or by changing the soil temperature or water 
content (Healy et al., 1996; Lund et al., 1999). In absorption-based closed static chamber techniques, the $\mathrm{CO}_{2}$ efflux is affected by two different mechanisms: by altered $\mathrm{CO}_{2}$ concentration inside the chamber and by lack of turbulence. When soil respiration is high the $\mathrm{CO}_{2}$ concentration inside the chamber and in the soil is high. At the same time, the lack of turbulence will have a large effect on the $\mathrm{CO}_{2}$ efflux, because the only mechanism of $\mathrm{CO}_{2}$ transport is then diffusion. This will create a severe underestimation. When the soil respiration is low, soda lime reduces $\mathrm{CO}_{2}$ concentration inside chamber headspace, typically below ambient, and the resulting larger concentration gradient causes overestimation of fluxes. This overestimation is partly offset by the reduced turbulence, but this is much less important when soil respiration is low because soil $\mathrm{CO}_{2}$ concentration is lower. These mechanisms can cause overestimation of low fluxes and underestimation of high fluxes (Janssens and Ceulemans, 1998).

In the closed static accumulation chamber, the $\mathrm{CO}_{2}$ concentration can exceed that of the ambient air. This saturation effect changes the natural concentration gradient within the soil surface and may reduce significantly the $\mathrm{CO}_{2}$ efflux (Nay et al., 1994; Livingston and Hutchinson, 1995; Davidson et al., 2002). So, this technique is known to underestimate the soil efflux (Janssens and Ceulemans, 1998).

In the closed dynamic system, the $\mathrm{CO}_{2}$ concentration in the chamber rises by a few tens of ppm above atmospheric value during the measurement (over a few minutes). The saturation effect generated is smaller than that in the static accumulation system and can be further reduced by passing the chamber air through a $\mathrm{CO}_{2}$ scrubber before the measurement record period. The perturbations of the concentration gradient can be minimized by starting the measurement just below and finishing just above the ambient $\mathrm{CO}_{2}$ concentration. This $\mathrm{CO}_{2}$ scrubbing technique is used, for example, in some Li-Cor chambers. The $\mathrm{CO}_{2}$ concentration in the chamber's headspace is scrubbed down by a few tens of ppm below the ambient target concentration by pumping the air in the chamber through an absorber column. Then the $\mathrm{CO}_{2}$ concentration is monitored as it rises above the target, and the $\mathrm{CO}_{2}$ efflux is calculated from the rate of increase of $\mathrm{CO}_{2}$ concentration at around the ambient concentration. With this technique, it is possible to avoid the effects of saturation on $\mathrm{CO}_{2}$ diffusion from the soil to the chamber. A good
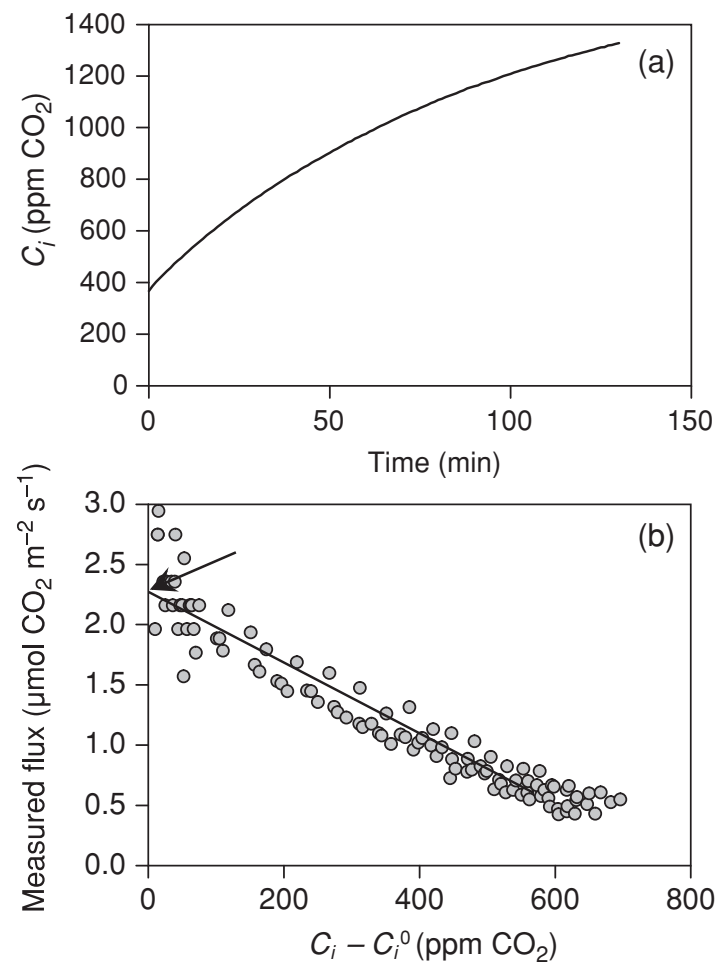

Figure 2.8 An example of the concentration development in a closed dynamic chamber (a) and the respective $\mathrm{CO}_{2}$ efflux plotted against the $\mathrm{CO}_{2}$ build-up within the chamber's headspace (b). The measured $\mathrm{CO}_{2}$ efflux decreases along with increasing $\mathrm{CO}_{2}$ concentration in the chamber due to the slow down in diffusion rate. The $\mathrm{CO}_{2}$ efflux decreases rapidly at the beginning of the measurement period. A peak in the $\mathrm{CO}_{2}$ efflux during the first minute or two of the measurement period may be due to pressure perturbations induced by the chamber or by the fan. After 1-2 minutes the $\mathrm{CO}_{2}$ efflux decreases linearly in relation to the concentration change in the chamber. In this case, the disturbance at the beginning of the measurement period could be corrected by interpolating linearly to zero in Fig. (b). The actual $\mathrm{CO}_{2}$ efflux from soil driven by diffusion is marked with an arrow.

indicator to see if saturation has a significant impact on the efflux is to detect the decrease in the slope of the time evolution of $\mathrm{CO}_{2}$ concentration or a low $\mathrm{r}^{2}$-value in the linear fit on $\Delta C / \Delta t$ (Fig. 2.1). The decrease in time evolution of $\mathrm{CO}_{2}$ concentration and soil $\mathrm{CO}_{2}$ efflux is illustrated in Fig. 2.8. The saturation effect should be taken into account when designing the dimensions of a closed chamber and the length of the measurement period. The volume vs. surface-area ratio of the chamber determines its sensitivity. For example, if the 
volume vs. surface-area ratio is low the system will detect even a small concentration increase and is thus applicable to measure small fluxes. However, in this case, the saturation of $\mathrm{CO}_{2}$ concentration will take place faster, which is a problem at high $\mathrm{CO}_{2}$ effluxes. Thus the volume vs. surface-area ratio should be designed bearing in mind the efflux range to be measured.

In the open dynamic system, the $\mathrm{CO}_{2}$ concentration in the chamber is constant but slightly above the ambient one. To make sure that the impact of this on the efflux is negligible, a closed dynamic chamber can be used for comparison. The slope of the time evolution of $\mathrm{CO}_{2}$ at the concentration recorded in the open system should be equal (very close) to the slope obtained at the ambient concentration (Longdoz et al., 2000).

\subsubsection{Horizontal wind}

The EC and gradient methods are the only ones that do not disturb the natural horizontal wind. Chambers are unable to reproduce natural wind conditions. In closed-static chambers (Edwards, 1982; Crill, 1991) wind velocity is zero. The only mechanism of $\mathrm{CO}_{2}$ transport is then diffusion. In dynamic-closed chambers and in open chambers wind velocity is determined by the airflow rate and by the chamber's design. Thus the boundary layer thickness and consequently the soil $\mathrm{CO}_{2}$ efflux will be altered. To our knowledge, the separate effect of this perturbation has not been studied systematically to date (this effect is difficult to distinguish from the PDC perturbation). Recently, Bain et al. (2005) studied the effect of horizontal wind speed on the PDC and found that horizontal wind induced substantial error in the $\mathrm{CO}_{2}$ efflux measurements also in closed dynamic chambers through the so-called 'Venturi effect', which was first reported by Conen and Smith (1998). In the Venturi effect, the wind movement around the vent of a closed chamber depressurizes the chamber by pulling air out of the chamber headspace resulting in a mass flow of soil gases from the porous soil into the chamber interior (Bain et al., 2005). This effect was shown to be very significant. According to Conen and Smith (1998), a steady wind speed of $2 \mathrm{~m} \mathrm{~s}^{-1}$ resulted in a $233 \%$ increase in measured soil emissions, and even in very calm conditions, with wind speed less than $1 \mathrm{~m} \mathrm{~s}^{-1}$, systematic errors of 10 to $50 \%$ were discovered. Similar results were later confirmed by Bain et al. (2005). The wind direction and speed on the soil surface usually fluctuates leading to unpredictable pressure variations inside the chamber. The Venturi effect and other anomalous pressure effects resulting from wind turbulence can be studied by testing the chamber vent and possible PDC by fast-response differential pressure sensor on a non-permeable plate and on different soil types and wind conditions. The pressure differences resulting from the Venturi effect may not be seen if the tests are conducted on a porous soil only, because the air flow through the porous soil into the chamber may compensate for the pressure loss in the chamber induced by the Venturi effect. Recently, $\mathrm{Xu}$ et al. (2006) suggested a new vent type for decreasing the Venturi effect in the chambers. The vent allows pressure inside the chamber to track pressure at the soil surface outside the chamber. The vent is designed so that it slows down the wind velocity within the vent such that the dynamic pressure changes induced by the wind are converted to static pressure, which the chamber equilibrates. They have tested this new vent design in field conditions with promising results.

\subsubsection{Other effects}

Usually chambers seal the soil surface either by pushing the chamber on or into the bare ground ('insertion method') or by placing the chamber on a collar penetrating the soil surface ('collar method'). This latter mode of chamber-soil contact assures airtight connection between the chamber and the soil, which is of advantage especially if the soil is porous and the measurement place is subjected to winds. Compared to the insertion of the chamber on the soil only, the collar has the advantage of reducing the risk of $\mathrm{CO}_{2}$ leakage out of the chamber and facilitates repeated measurements on the same spot. However, the drawback of collars is that roots are cut during insertion into the soil (the trenching effect). Consequently, because roots contribute significantly to soil respiration (Hanson et al., 2000), the soil $\mathrm{CO}_{2}$ concentration and the efflux will be affected. To reduce the trenching effect, the collars should not be pushed down into the rooting zone. If this cannot be avoided, the collars should be left in place until the roots have re-grown inside the collar. The recovery of fine roots may take several years. Makkonen and Helmisaari (1999) studied fine-root biomass growth with root ingrowth core method in a boreal forest. The ingrowth cores were initially without root biomass and 
no levelling off in the biomass growth was found during the first three growing seasons. If installed very deeply in the soil, the collars may produce a similar effect. However, most of the damage may be mitigated by flat collars that have spikes to keep the collar grounded but do not trench the whole root system.

Recent studies confirmed that the chamber-soil contact mode has a significant impact on the apparent soil respiration rates (Ngao et al., 2006) with generally higher values obtained for the 'insertion' mode. Even if both chamber-soil contact modes have advantages and disadvantages, it can be concluded that the advantages of using a collar prevail. Therefore, the use of collars is recommended.

The heating of the chambers in the sun when the measurement time is long and the chamber is transparent can affect the temperature and water status of the ground vegetation and soil surface inside the chamber. The temperature can increase by up to 10 to 15 ${ }^{\circ} \mathrm{C}$ during chamber closure on a warm, sunny day. This may disturb the respiration rate and results in changes in the $\mathrm{CO}_{2}$ concentration gradient. Therefore, a thermostatically controlled cooling system would be recommended, especially if the chamber is transparent and closed. Heating of the chambers in the sun should also be taken into consideration as a possible cause of pressure-gradient perturbation, especially when the measurement time is long and the chamber is transparent. The temperature increase results in a physical expansion of air inside the chamber, which may result in an overpressure blocking soil efflux and creating a mass flow of $\mathrm{CO}_{2}$ out of the chamber through the equilibrium tube or through the soil.

\subsection{COMPARISON OF THE EXISTING SYSTEMS AND RECOMMENDATIONS}

Several recent studies compared the accuracy of different systems. Janssens et al. (2000) as well as Shibistova et al. (2002) found systematically lower values of soil respiration measured by ground level EC compared to chamber measurements. In the study by Janssens et al. (2000) this underestimation was correlated with photosynthetically active radiation (PAR), suggesting a confounding effect of the ground vegetation. Chamber comparisons were either conducted in the field by comparing the apparent fluxes at the same collars (Janssens et al., 2000), by artificial systems with known fluxes
(Pumpanen et al., 2004) or by a combination of both (Butnor et al., 2005). The comparisons have indicated relative differences between chamber types (Raich et al., 1990; Norman et al., 1997; Janssens et al., 2000; Pumpanen et al., 2004) or showed chamber-specific limitations (Nay et al., 1994; Fang and Moncrieff, 1998; Gao and Yates, 1998).

In most cases, closed dynamic and static chambers have been shown to give systematically lower values than open dynamic chambers - the difference ranging from $10 \%$ (Rayment, 2000) to $40-50 \%$ (Norman et al., 1997; Pumpanen et al., 2003a). However, in a recent study (Pumpanen et al., 2004), the differences between chambers using different measurement principles seemed not to be consistent. When most of the currently available chamber systems were compared against known $\mathrm{CO}_{2}$ effluxes generated by a calibration chamber in laboratory conditions, their reliability appeared to be independent of the measurement principle as such (Pumpanen et al., 2004). Instead, the geometrical design of the chamber, the mixing of air inside the chamber and the collar model seemed to affect the measured $\mathrm{CO}_{2}$ efflux more than the measurement principle. Even identical chambers with different collar designs showed highly variable results. However, the general trend seemed to be that closed static chambers underestimated $\mathrm{CO}_{2}$ effluxes by 4 to $14 \%$. No systematic differences were found between open dynamic chambers and closed dynamic chambers (Pumpanen et al., 2004). An extract from the recent paper by Pumpanen $e t$ al. (2004) is presented in Table 2.1. In Table 2.2, we have listed the advantages and disadvantages of the major chamber systems. A standard chamber will hardly be available, because different ecosystems require different chamber designs. One technical solution may not be the best for all purposes. For example, a small chamber suitable for forest with abundance of stones and small shrub vegetation is probably not suitable for measuring grasslands. The only reasonable way to standardize various chamber systems is to compare them against known $\mathrm{CO}_{2}$ effluxes.

In conclusion, the method used for measuring soil $\mathrm{CO}_{2}$ efflux should be chosen based on the research conducted and the type of ecosystem (see Section 2.5). The chamber methods affect the flux being measured, but this error can be detected and corrected if the chambers are tested against known $\mathrm{CO}_{2}$ effluxes. Reliable $\mathrm{CO}_{2}$ efflux measurements can be carried out with open as 


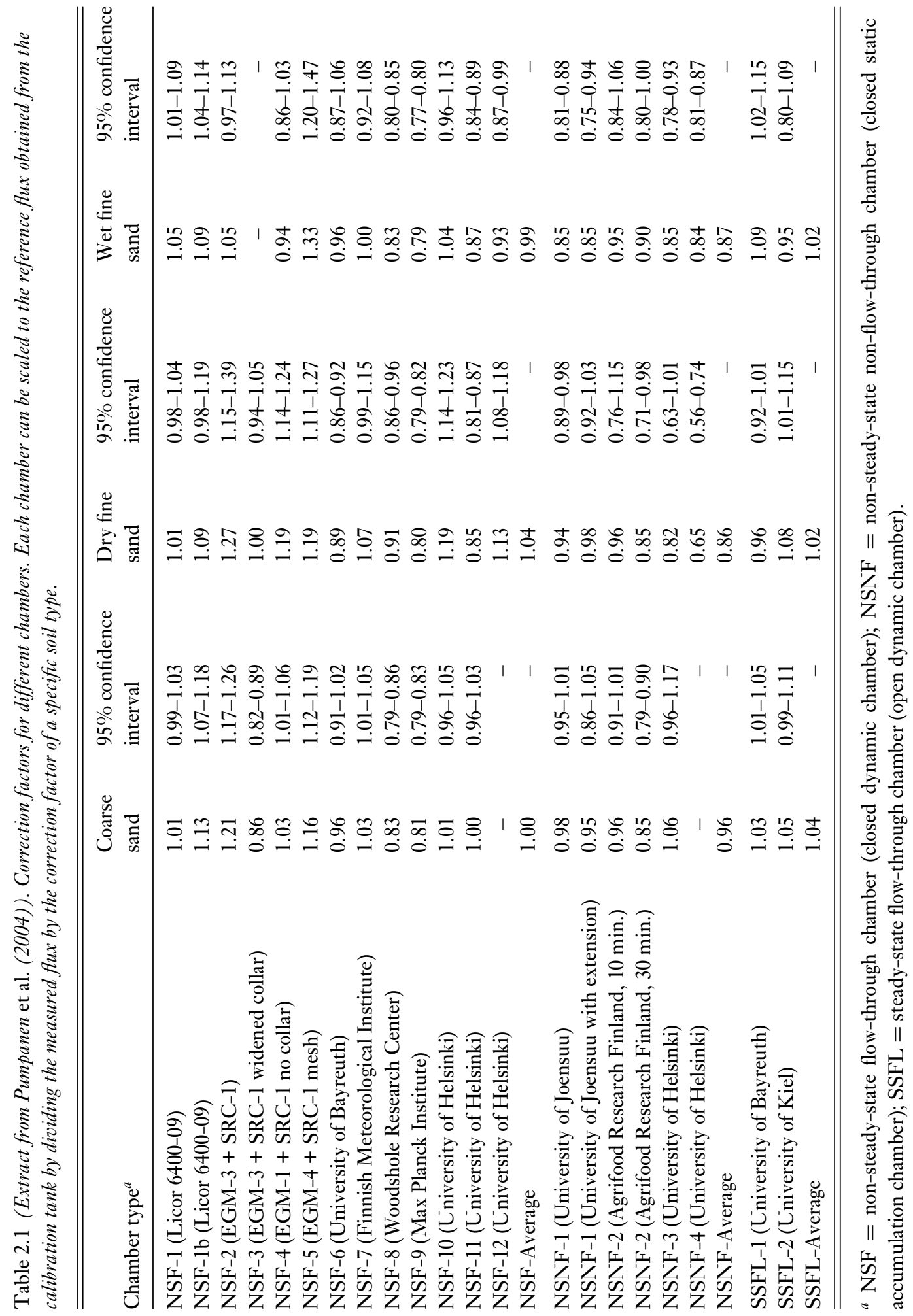




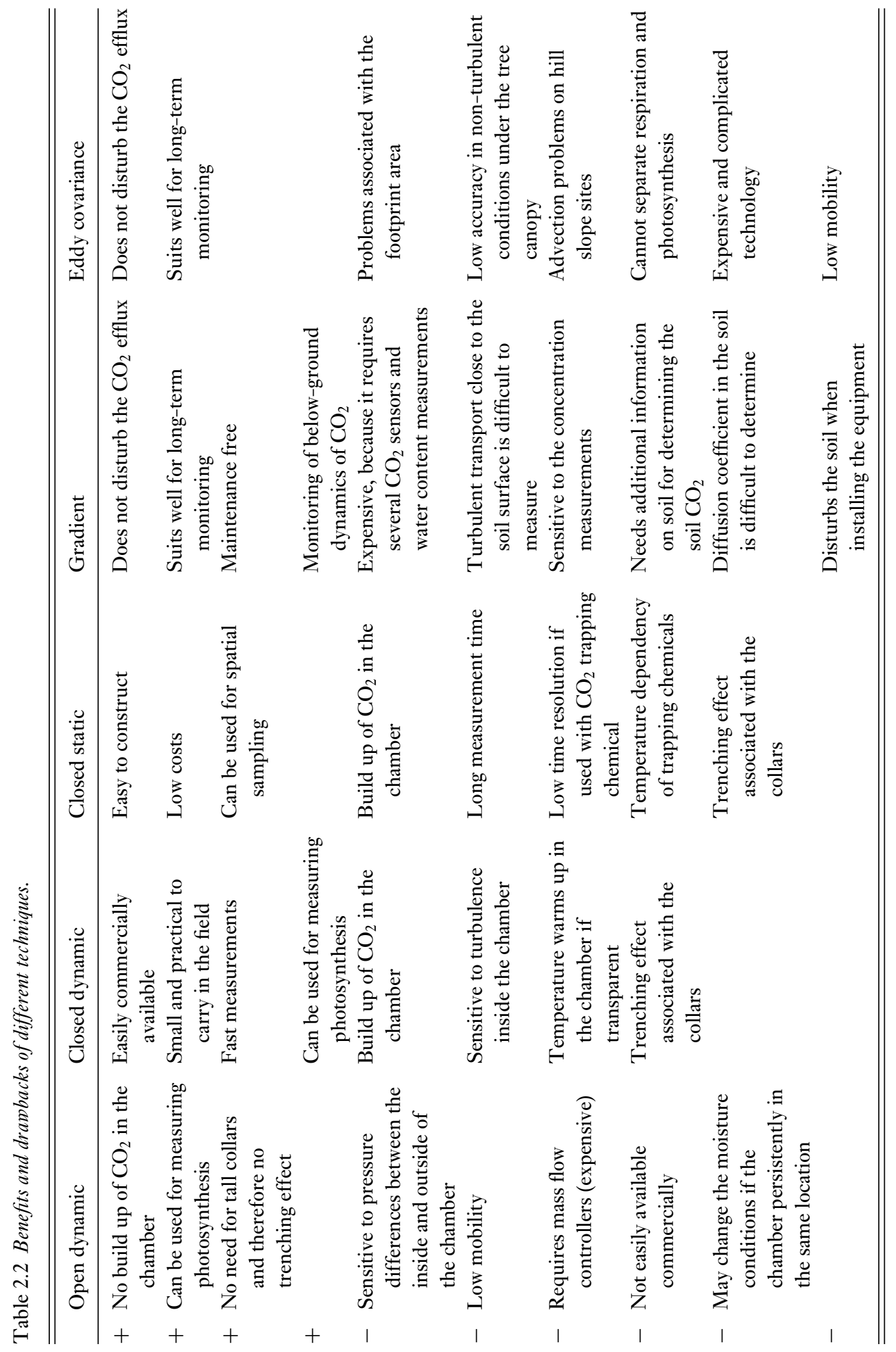


well as with closed dynamic chambers if the chamber is designed taking into account the following issues.

- Special attention should be paid to the mixing of air within the chamber, because it can be a major source of error. Excessive turbulence inside the chamber can cause over- or underpressure compared to natural ambient conditions, which can lead to artificial mass flow of $\mathrm{CO}_{2}$ between soil and the chamber. This is particularly important when using closed dynamic chambers where the $\mathrm{CO}_{2}$ concentration has to be evenly distributed within the chamber in order to calculate the flux correctly. The air mixing should be efficient enough to provide homogeneous $\mathrm{CO}_{2}$ concentration within the chamber's headspace, but weak enough not to cause pressure anomalies.

- The headspace concentration inside the chamber affects the flux by altering the concentration gradient between the soil and the chamber, and therefore the chamber should be designed so that the increase in $\mathrm{CO}_{2}$ concentration of the chamber headspace is as small as possible.

- Collars, which are the recommended chamber-soil contact method, should be designed for minimum disturbance of the root system. This can be solved in different ways either by using spikes or by a sufficient delay between collar insertion and measurement.

\subsection{EXPERIMENTAL DESIGN}

The experimental design of a measurement campaign depends on the space and time scales studied. The measurement system and protocol have to be adapted to the type of ecosystems in which the soil $\mathrm{CO}_{2}$ efflux measurements are performed. In studies requiring continuous monitoring of soil $\mathrm{CO}_{2}$ efflux over a long time period, the measurement technique should cause minimum disturbance on the soil. Unfortunately, most of the chamber techniques cannot fulfil this requirement. The eddy covariance technique would be an ideal method for long-term monitoring, because, unlike the chamber methods, it does not affect the processes underlying soil $\mathrm{CO}_{2}$ effluxes. It is efficient for analyzing the time evolution with small time steps (halfhour) even over a long time period but only in open forests (Baldocchi and Vogel, 1996; Black et al., 1996; Law et al., 1999) and for an area of several square metres.
Another method causing relatively small disturbance of the measurement object is the gradient method. However, the use of this method is rather uncommon because the flux data are very sensitive to the soil diffusivity, a parameter that is difficult to determine, and to the accuracy of the $\mathrm{CO}_{2}$ concentration measurements. The accuracy of this method is still debatable. However, on grasslands and in forests with dense ground vegetation it could be a good alternative, because EC and chambers do not dissociate ground vegetation exchange and soil $\mathrm{CO}_{2}$ efflux. The gradient method is better suited for long-term monitoring of $\mathrm{CO}_{2}$ effluxes from a relatively small surface area rather than for determining statistically representative flux estimates over a large area. This is because the soil diffusivity and soil air $\mathrm{CO}_{2}$ concentration often vary at the small spatial scale and the equipment needed to capture this spatial variability would be rather expensive, especially if the area to be measured were heterogeneous. The gradient method is at its best when studying the $\mathrm{CO}_{2}$ effluxes on a process level. The gradient measurement itself does not disturb the $\mathrm{CO}_{2}$ efflux after the initial disturbance from the installation of the measurement devices. The devices should be installed in an undisturbed soil, by soil core removing, and should avoid as much as possible root cutting and modifications in the diffusion properties of the soil. However, at the same time, continuous vertical pathways from the $\mathrm{CO}_{2}$ sensors to the soil surface should be avoided, because they change the hydraulic properties of the soil by providing a water passage from the soil surface to the sensor. In addition, the $\mathrm{CO}_{2}$ diffusion along these vertical pathways may be faster than in the natural soil. This can result in erroneous $\mathrm{CO}_{2}$ concentration measurements and consequently lead to biased $\mathrm{CO}_{2}$ efflux estimates.

In view of the difficulties met by the gradient method (see above), the dynamic chamber systems (open or closed) appear to be the most adequate on vegetated soil. The open chamber measures with a high temporal resolution but has to fulfil some requirements before being applicable for long-term measurements. After a few days the soil conditions (temperature and water content) can be significantly affected by the perpetual presence of the chamber if the chamber top is not opened in between the measurements. If opened between the measurements, the open dynamic chamber needs some time to reach steady-state conditions. This equilibrium time depends on the flow rate and on 
the $\mathrm{CO}_{2}$ efflux. In addition, the surface area that can be sampled by the open chamber is small because one chamber covers only a few tens to hundreds of square centimetres and the scaling-up of the system is often expensive. Therefore, open chambers may not be the best in studies requiring good spatial coverage.

Spatial sampling is often carried out with portable chambers. The closed static chamber systems have largely been abandoned because of the systematic errors in this technique (the tendency to underestimate the efflux). For spatial sampling, manual or automated closed dynamic chambers may be a better option. Manual chambers can be moved from one collar to another by the experimenter. Because the measurement time is relatively short, he or she is able to collect data representing the efflux of up to one or more hectares in one day. In this condition, it is possible to integrate the spatial variability of an entire plot. However, this integration is done to the detriment of the temporal resolution of the measurement on the same spot. Temporal changes in soil respiration have to be taken into consideration when studying the spatial variation with manual chambers. Ideally, the temperature fluctuation during the spatial sampling should be as small as possible. The measurements carried out at different temperature conditions on different measurement collars cannot be used for averaging the efflux over the whole measurement plot, or at least the $\mathrm{CO}_{2}$ efflux values measured from individual collars should be corrected for the difference in temperature. This in turn requires information on the temperature response of the individual collars.

Best results can probably be obtained by combining continuous monitoring of $\mathrm{CO}_{2}$ efflux with automated chambers and spatial measurements with manual chambers. This way, it is possible to obtain both good temporal resolution and spatial representativeness. There are already automatic closed chambers available, which are attached to one collar at a time and measured at a chosen frequency. Then the short-term $\mathrm{CO}_{2}$ evolution (half-hour) can be obtained over a long time period (season or even year) from a number of points depending on the financial resources. However, the representative area sampled cannot be as large as with a manual system.

The experimental design and the measurement protocol applied in individual studies is usually a trade-off between the technical and human resources available. It is the experimenter's task to plan the measurements so that they, on the one hand, provide enough information on spatial variation for sound statistical analysis and, on the other hand, provide data with high enough temporal resolution for studying the processes underlying soil $\mathrm{CO}_{2}$ efflux and all this with feasible costs. We hope that the issues discussed in this chapter will help the reader to solve this equation.

\section{REFERENCES}

Albertsen, M. (1979) Carbon dioxide balance in the gas-filled part of the unsaturated zone, demonstrated at a Podzol. Z Pflanzen Bodenk, 142, 39-56.

Aubinet, M., Grelle, A., Ibrom, A. et al. (2000) Estimates of the annual net carbon and water exchange of forests: the EUROFLUX methodology. Advances in Ecological Research, 30, 113-75.

Bain, W. G., Hutyra, L., Patterson, D. C. et al. (2005)

Wind-induced error in the measurement of soil respiration using closed dynamic chambers. Agricultural and Forest Meteorology, 131, 225-32.

Baldocchi, D. D. and Vogel, C. A. (1996) Energy and $\mathrm{CO}_{2}$ flux densities above and below a temperate broad-leaved forest and boreal pine forest. Tree Physiology, 16, 5-16.

Black, T. A., den Hartog, G., Neumann, H. H. et al. (1996) Annual cycles of water vapour and carbon dioxide fluxes in and above a boreal aspen forest. Global Change Biology, 2, 219-29.

Butnor, J. R., Johnsen, K. H. and Maier, C. A. (2005) Soil properties differently influence estimates of soil $\mathrm{CO}_{2}$ efflux from three chamber-based measurement systems. Biogeochemistry, 73, 283-301.

Conen, F. and Smith, K. A. (1998) A re-examination of closed flux chamber methods for the measurement of trace gas emissions from soils to the atmosphere. European Fournal of Soil Science, 49, 701-7.

Crill, P. M. (1991) Seasonal pattern cycles of methane uptake and carbon dioxide release by a temperate woodland soil. Global Biogeochemistry, 5, 319-34.

Davidson, E. A., Savage, K., Verchot, L. V. and Navarro, R. (2002) Minimizing artifacts and biases in chamber-based measurements of soil respiration. Agricultural and Forest Meteorology, 113, 21-37.

De Jong, E., Redmann, R. E. and Ripley, E. A. (1979) A comparison of methods to measure soil respiration. Soil Science, 127, 300-6.

Edwards, N. T. (1974) A moving chamber design for measuring soil respiration rates. Oikos, 25, 97-101. 
Edwards, N. T. (1982) The use of soda-lime for measuring respiration rates in terrestrial ecosystems. Pedobiologia, 23, 321-30.

Edwards, N. T. and Sollins, P. (1973) Continuous measurements of carbon dioxide evolution from partitioned forest floor components. Ecology, 54, 406-12.

Fang, C. and Moncrieff, J. B. (1996) An improved dynamic chamber technique for measuring $\mathrm{CO}_{2}$ efflux from the surface of soil. Functional Ecology, 10, 297-305.

Fang, C. and Moncrieff, J. B. (1998) An open-top chamber for measuring soil respiration and the influence of pressure difference on $\mathrm{CO}_{2}$ efflux measurement. Functional Ecology, 12, 319-25.

Fang, C. and Moncrieff, J. B. (1999) A model for soil $\mathrm{CO}_{2}$ production and transport 1: Model development. Agricultural and Forest Meteorology, 95, 225-36.

Fernandez, I. J. and Kosian, P. A. (1987) Soil air carbon dioxide concentrations in a New England spruce-fir forest. Soil Science Society of America fournal, 51, 261-3.

Freijer, J. I. and Leffelaar, P. A. (1996) Adapted Fick's law applied to soil respiration. Water Resources Research, 32, 791-800.

Gao, F. and Yates, S. R. (1998) Laboratory study of closed and dynamic flux chambers: experimental results and implications for field application. Fournal of Geophysical Research, 103, 26115-25.

Goulden, M. L. and Crill, P. M. (1997) Automated measurements of $\mathrm{CO}_{2}$ exchange at the moss surface of a black spruce forest. Tree Physiology, 17, 537-42.

Grogan, P. (1998) $\mathrm{CO}_{2}$ flux measurement using soda lime: correction for water formed during $\mathrm{CO}_{2}$ adsorption. Ecology, 79, 1467-8.

Haber, W. (1958) Ökologische Untersuchung der Bodenatmung. Mit einer Übersicht über frühere Bearbeitungen, insbesondere deren Methoden. Flora, 146, 109-57.

Hanson, P. J., Edwards, N. T., Garten, C. T. and Andrews, J. A. (2000) Separating root and soil microbial contributions to soil respiration: a review of methods and observations. Biogeochemistry, 48, 115-46.

Healy, R. W., Striegl, R. G., Russell, T. F., Hutchinson, G. L. and Livingston, G. P. (1996) Numerical evaluation of static-chamber measurements of soil-atmosphere gas exchange: identification of physical processes. Soil Science Society of America Fournal, 60, 740-7.

Iritz, Z., Lindroth, A. and Gärdenäs, A. (1997) Open ventilated chamber system for measurements of $\mathrm{H}_{2} \mathrm{O}$ and $\mathrm{CO}_{2}$ fluxes from the soil surface. Soil Technology, 10, 169-84.

Janssens, I. A. and Ceulemans, R. (1998) Spatial variability in forest soil $\mathrm{CO}_{2}$ efflux assessed with a calibrated soda lime technique. Ecology Letters, 1, 95-8.

Janssens, I. A., Kowalski, A. S., Longdoz B. and Ceulemans, R. (2000) Assessing forest soil $\mathrm{CO}_{2}$ efflux: an in situ comparison of four techniques. Tree Physiology, 20, 23-32.

Janssens, I. A., Kowalski, A. S. and Ceulemans, R. (2001) Forest floor $\mathrm{CO}_{2}$ fluxes estimated by eddy covariance and chamber-based model. Agricultural and Forest Meteorology, 106, 61-9.

Jassal, R. S., Black, T. A., Drewitt, G. B. et al. (2004) A model of the production and transport of $\mathrm{CO}_{2}$ in soil: predicting soil $\mathrm{CO}_{2}$ concentrations and $\mathrm{CO}_{2}$ efflux from a forest floor. Agricultural and Forest Meteorology, 124, 219-36.

Kanemasu, E. T., Powers, W. L. and Sij, J. W. (1974) Field chamber measurements of $\mathrm{CO}_{2}$ efflux from soil surface. Soil Science, 118, 233-7.

Kelliher, F. M., Lloyd, J., Arneth, A. et al. (1999) Carbon dioxide efflux density from the floor of a central Siberian pine forest. Agricultural and Forest Meteorology, 94, 217-32.

Koepf, H. (1953a) Die Verwendung eines Ultrarotabsorptionsschreibers (URAS) für die kontinuierliche Registrierung der Bodenatmung im Freiland. Landwirtschaftliche Forschung, 5, 54-62.

Koepf, H. (1953b) Die Temperatur/Zeit - Abhängigkeit der Bodenatmung. Experimentelle Untersuchung unter Verwendung des Ultrarotabsorptionsschreibers (URAS). Zeitung für Pflanzenernährung, Düngung, Bodenkunde, 61, 29-47.

Koepf, H. (1954) Die biologische Aktivität des Bodens und ihre experimentelle Kennzeichnung. Zeitung für Pflanzenernährung, Düngung, Bodenkunde, 64, 138-46.

Kutsch, W. L. (1996) Untersuchung zur Bodenatmung zmeier Ackerstandorte im Bereich der Bornhöveder Seenkette. EcoSys. Beiträge zur Ökosystemforschung, Vol. Suppl. 16. Kiel: Verein zur Förderung der Ökosystemforschung.

Kutsch, W. L. and Kappen, L. (1997) Aspects of carbon and nitrogen cycling in soils of the Bornhoved lake district. 2. Modelling the influence of temperature increase on soil respiration and organic carbon content in arable soils under different managements. Biogeochemistry, 39, 207-24. 
Kutsch, W. L., Staack, A., Wötzel, J., Middelhoff, U. and Kappen, L. (2001) Field measurements of root respiration and total soil respiration in an alder forest. New Phytologist, 150, 157-68.

Law, B. E., Baldocchi, D. D. and Anthoni, P. M. (1999) Below-canopy and soil $\mathrm{CO}_{2}$ fluxes in a ponderosa pine forest. Agricultural and Forest Meteorology, 94, 171-88.

Livingston, G. P. and Hutchinson, G. L. (1995)

Enclosure-based measurement of trace gas exchange: applications and sources of error. In Methods in Ecology, Biogenic Trace Gases: Measuring Emissions from Soil and Water, ed. P. A. Matson and R. C. Harris. Cambridge: Blackwell Science, pp. 14-50.

Longdoz, B., Yernaux, M. and Aubinet, M. (2000) Soil $\mathrm{CO}_{2}$ efflux measurements in a mixed forest: impact of chamber disturbances, spatial variability and seasonal evolution. Global Change Biology, 6, 907-17.

Lund, C. P., Riley, W. J., Pierce, L. L. and Field, C. B. (1999) The effects of chamber pressurization on soil-surface $\mathrm{CO}_{2}$ flux and the implications for NEE measurements under elevated $\mathrm{CO}_{2}$. Global Change Biology, 5, 269-81.

Lundegårdh, H. (1922) Neue Apparate zur Analyse des Kohlensäuregehalts der Luft. Biochem Z, 131, 109.

Lundegårdh, H. (1924) Der Kreislauf der Kohlensäure in der Natur. Ein Beitrag zur Pflanzenökologie und zur Landwirtschaftlichen Düngungslehre. Jena: Verlag von Gustav Fischer.

Lundegårdh, H. (1927) Carbon dioxide evolution of soil and crop growth. Soil Science, 23, 417-53.

Makkonen, K. and Helmisaari, H. S. (1999) Assessing fine-root biomass and production in a Scots pine stand: comparison of soil core and root ingrowth core methods. Plant Soil, 210, 43-50.

Mykeebust, M. C., Hipps, L. E. and Ryel, R. J. (2008) Comparison of eddy covariance, chamber, and gradient methods of measuring soil $\mathrm{CO}_{2}$ efflux in an annual semi-arid grass, Bromus tectorum. Agricultural and Forest Meteorology, 148, 1894-907.

Nay, M. S., Mattson, K. G. and Bormann, B. T. (1994) Biases of chamber methods for measuring soil $\mathrm{CO}_{2}$ efflux demonstrated with a laboratory apparatus. Ecology, 75, 2460-3.

Ngao, J., Longdoz, B., Perrin, D. et al. (2006) Cross-calibration functions for soil $\mathrm{CO}_{2}$ efflux measurement systems. Annals of Forest Science, 63, 477-84.

Norman, J. M., Garcia, R. and Verma, S. B. (1992) Soil surface $\mathrm{CO}_{2}$ fluxes and the carbon budget of a grassland. Journal of Geophysical Research, 97, 18845-53.

Norman, J. M., Kucharik, C. J., Gower, S. T. et al. (1997) A comparison of six methods for measuring soil-surface carbon dioxide fluxes. Fournal of Geophysical ResearchAtmospheres, 102, 28771-7.

Pihlatie, M., Pumpanen, J., Rinne, J. et al. (2007) Gas concentration driven fluxes of nitrous oxide and carbon dioxide in boreal forest soil. Tellus Series B-Chemical and Physical Meteorology, 59, 458-69.

Porkka, O. H. (1931) Über eine neue Methode zur Bestimmung der Bodenatmung. Ann Soc Zool-Bot Fenn Yanamo, 15, 101-18.

Pumpanen, J., Ilvesniemi, H., Keronen, P. et al. (2001) An open chamber system for measuring soil surface $\mathrm{CO}_{2}$ efflux: analysis of error sources related to the chamber system. Fournal of Geophysical Research, 106, 798592.

Pumpanen, J., Ilvesniemi, H., Peramaki, M. and Hari, P. (2003a) Seasonal patterns of soil $\mathrm{CO}_{2}$ efflux and soil air $\mathrm{CO}_{2}$ concentration in a Scots pine forest: comparison of two chamber techniques. Global Change Biology, 9, 371-82.

Pumpanen, J., Ilvesniemi H. and Hari, P. (2003b) A process-based model for predicting soil carbon dioxide efflux and concentration. Soil Science Society of America Fournal, 67, 402-13.

Pumpanen, J., Kolari, P., Ilvesniemi, H. et al. (2004) Comparison of different chamber techniques for measuring soil $\mathrm{CO}_{2}$ efflux. Agricultural and Forest Meteorology, 123, 159-76.

Raich, J. W., Bowden, R. D. and Steudler, P. A. (1990) Comparison of two static chamber techniques for determining carbon dioxide efflux from forest soils. Soil Science Society of America Fournal, 54, 1754-7.

Rayment, M. B. (2000) Closed chamber systems underestimate soil $\mathrm{CO}_{2}$ efflux. European Fournal of Soil Science, 51, 107-10.

Rayment, M. B. and Jarvis, P. G. (1997) An improved open chamber system for measuring soil $\mathrm{CO}_{2}$ effluxes in the field. Fournal of Geophysical Research, 102, 28779-84.

Rochette, P., Gregorich, E. G. and Desjardins, R. L. (1992) Comparison of static and dynamic closed chambers for measurement of soil respiration under field conditions. Canadian Fournal of Soil Science, 72, 605-9. 
Rochette, P., Ellert, B., Gregorich, E. G. et al. (1997)

Description of a dynamic closed chamber for measuring soil respiration and its comparison with other techniques. Canadian Fournal of Soil Science, 77, 195-203.

Savage, K. E. and Davidson, E. A. (2003) A comparison of manual and automated systems for soil $\mathrm{CO}_{2}$ flux measurements: trade-offs between spatial and temporal resolution. Fournal of Experimental Botany, 54, 891-9.

Schwartzkopf, S. H. (1978) An open chamber technique for the measurement of carbon dioxide evolution from soils. Ecology, 59, 1062-8.

Shibistova, O., Lloyd, J., Zrazhevskaya, G. et al. (2002) Annual ecosystem respiration budget for a Pinus sylvestris stand in central Siberia. Tellus Series B, 54, $568-89$.

Striegl, R. G., McConnaughey, T. A., Thorstenson, D. C., Weeks, E. P. and Woodward, J. C. (1992) Consumption of atmospheric methane by desert soils. Nature, 337, $145-7$.

Suarez, D. L. and Šimunek, J. (1993) Modeling of carbon dioxide transport and production in soil 2. Parameter selection, sensitivity analysis and comparison of model predictions to field data. Water Resources Research, 29, 499-513.
Takle, E. S., Massman, W. J., Brandle, J. R. et al. (2004) Influence of high-frequency ambient pressure pumping on carbon dioxide efflux from soil. Agricultural and Forest Meteorology, 124, 193-206.

Tang, J., Misson, L., Gershenson, A., Cheng, W. and Goldstein, A. H. (2005) Continuous measurements of soil respiration with and without roots in a ponderosa pine plantation in the Sierra Nevada Mountains. Agricultural and Forest Meteorology, 132, 212-27.

Tang, J. W., Baldocchi, D. D., Qi, Y. and Xu, L. K. (2003) Assessing soil $\mathrm{CO}_{2}$ efflux using continuous measurements of $\mathrm{CO}_{2}$ profiles in soils with small solid-state sensors. Agricultural and Forest Meteorology, 118, 207-20.

Witkamp, M. (1969) Cycles of temperature and carbon dioxide evolution from litter and soil. Ecology, 50, 922-4.

Witkamp, M. and Frank, M. L. (1969) Evolution of $\mathrm{CO}_{2}$ from litter, humus, and subsoil of a pine stand. Pedobiologia, 9, 358-65.

Xu, L., Furtaw, M. D., Madsen, R. A. et al. (2006) On maintaining pressure equilibrium between a soil $\mathrm{CO}_{2}$ flux chamber and the ambient air. Fournal of Geophysical Research, 111, D08S10, doi:10.1029/ 2005JD006435. 